\title{
LA ARGENTINA POSCONVERTIBILIDAD: MODELO DE ACUMULACIÓN
}

\author{
Gastón Ángel Varesi*
}

Fecha de recepción: 18 de septiembre de 2009. Fecha de aceptación: 24 de febrero de 2010.

\section{Resumen}

El artículo analiza las principales características del modelo de acumulación Posconvertibilidad en Argentina (2002-2009), partiendo de su configuración inicial y reflexionando acerca de las tensiones suscitadas en el contexto de crisis mundial. En el análisis de las políticas fundacionales del modelo actual, se observan las variaciones en la correlación de fuerzas entre las distintas fracciones de clases en un nivel estructural. Se hace énfasis en el papel del Estado en la gestación de un sistema de transferencias de ingresos entre las distintas fracciones de clase, buscando constituir un nuevo momento conciliatorio. En este punto, se incorpora la dimensión de la crisis mundial indagando acerca de las políticas anticrisis aplicadas en el ámbito nacional y sus implicaciones tanto respecto del modelo de acumulación como de las fracciones de clase.

Palabras clave: modelo de acumulación, políticas económicas, clases sociales, Argentina, crisis mundial.

* Sociólogo por la Universidad Nacional de La Plata (UNLP). Becario del Consejo Nacional de Investigaciones Científicas y Técnicas (Conicet). Investigador del Centro de Investigaciones Sociales y Humanas, Facultad de Humanidades y Ciencias de la Educación de la UNLP. Coordinador del equipo de investigación sobre estructura de clase, modelo de acumulación y políticas económicas de la Fundación de Investigaciones Sociales y Políticas. Correo electrónico: gastonvaresi@hotmail.com 
Abstract

The article analyzes the major features of Argentina's post-convertibility accumulation model (2002-2009), beginning with its initial configuration and reflecting on the tensions stirred up in the context of the world crisis. Analyzing the fundamental policies of the present model, we see variations in the correlation of forces between different class fractions at a structural level. Emphasis is put on the role of the State in managing a system of income transfers between distinct class fractions, seeking to constitute a new moment of reconciliation. On this point, the dimension of the world crisis includes an enquiry into the anti-crisis policies applied within the national orbit and their implications with respect to both the accumulation model and the class fractions.

Keywords: accumulation model, economic policies, social classes, Argentina, world crisis.

\section{Résumé}

L'article analyse les principales caractéristiques du modèle d'accumulation Postconvertibilité en Argentine (2002-2009), en partant de sa configuration initiale et en s'interrogeant sur les tensions suscitées dans le contexte de la crise mondiale. Dans l'analyse des politiques fondatrices du modèle actuel, on observe les variations survenues dans la corrélation des forces entre les distinctes fractions de classes à un niveau structurel. Il est mis l'accent sur le rôle de l'État dans la gestation d'un système de transfert de revenus entre les distinctes fractions de classe visant à créer un nouveau moment conciliatoire. Enfin, la dimension de la crise mondiale est incorporée à cette étude à travers l'examen des politiques anticrise appliquées au niveau national et leurs implications tant quant au modèle d'accumulation qu'en ce qui concerne les divisions de classe.

Mots clés: modèle d'accumulation, politiques économiques, classes sociales, Argentine, crise mondiale.

\section{Resumo}

$O$ artigo analisa as principais características do modelo de acumulação Pós-convertibilidade na Argentina (2002-2009), partindo da sua configuração inicial e refletindo sobre as tensões suscitadas no contexto da crise mundial. Na análise das políticas fundacionais do modelo atual, observam-se as variações na correlação de forças entre as distintas frações de classes num nível estrutural. Coloca-se ênfase no papel do Estado na gestação de um sistema de transferências de ingressos entre as distintas frações de classe, buscando constituir um novo momento conciliatório. Neste ponto, incorporase a dimensão da crise mundial indagando sobre as políticas anticrise aplicadas em ámbito nacional e suas implicações tanto com respeito ao modelo de acumulação como ao das frações de classe.

Palavras-chave: modelo de acumulação, políticas econômicas, classes sociais, Argentina, crise mundial. 


\section{Introducción}

1 presente artículo analiza las características principales del modelo de acumu-
lación posconvertibilidad en Argentina, 2002-2009, partiendo de su configu-
ración inicial y reflexionando acerca de las tensiones suscitadas en el contexto de crisis mundial.

Con este objetivo realizaremos una aproximación al marco conceptual en el que se asienta el trabajo. A continuación, daremos cuenta de algunos factores que signaron la caída del modelo de Convertibilidad (1991-2001). Luego, señalaremos las políticas fundacionales del modelo actual, observando las variaciones en la correlación de fuerzas entre distintas fracciones de clases en un nivel estructural. Haremos énfasis en el papel del Estado en la gestación de un sistema de transferencias de ingresos entre las fracciones de clase, buscando constituir un nuevo momento conciliatorio. Una vez establecidos los principales aspectos de la dinámica socioeconómica posconvertibilidad, incorporaremos la dimensión de la crisis mundial, observando las políticas anticrisis aplicadas en el ámbito nacional y extraeremos las conclusiones pertinentes.

\section{Desafíos conceptuales: modelo de acumulación}

Nuestro problema de investigación exige el análisis de tres núcleos conceptuales: modelo de acumulación, políticas económicas y relaciones de fuerzas entre fracciones de clase. La articulación de dichos núcleos se realizará con el modelo de acumulación como unidad de análisis principal, en tanto las políticas económicas y las fracciones de clase serán tomadas como subunidades que serán tratadas para explicar el modelo de acumulación.

Un primer desafío presente en nuestro estudio se refiere a la ausencia de una conceptualización explícita y sistemática del modelo de acumulación como concepto. Aunque éste se emplea en numerosos trabajos, su vaguedad y polisemia son notorias. Esbozaremos una definición del mismo, mostrando su íntima relación con los otros dos núcleos conceptuales básicos. En este camino, parece importante rescatar la definición de Basualdo (2007) sobre un concepto emparentado: régimen o patrón de acumulación dominante. Según Basualdo, "se trata de una categoría muy abarcativa que exhibe un significativo nivel de abstracción. No obstante es necesario analizarlo porque se trata de un instrumento analítico sumamente trascendente al permitir diferenciar los distintos comportamientos económicos que se suceden en el tiempo. Esto es posible debido a que este concepto alude a la articulación de un determinado funcionamiento de las variables económicas, vinculado a una 
definida estructura económica, una peculiar forma de Estado y las luchas entre los bloques sociales existentes" (Basualdo, 2007: 6, énfasis en el original). Notamos que en esta aproximación aparecen dimensiones relevantes propias de nuestro problema: el Estado, al que nos acercaremos mediante el análisis de la política económica; la lucha entre bloques sociales y la estructura económica, que trataremos a partir del análisis de la correlación de fuerzas entre fracciones de clase en un nivel estructural, según la propuesta teórica gramsciana ${ }^{1}$. Basualdo señala dos factores principales para determinar un régimen de acumulación: "Es preciso indicar que las variables económicas para poder constatarse la existencia de un patrón de acumulación de capital deben cumplir dos requisitos: la regularidad en su evolución y la existencia de un orden de prelación entre ellas" (Basualdo, 2007: 6, énfasis en el original). Los criterios de regularidad y orden de prelación (o sea, la relación jerárquica según su relevancia explicativa) entre las variables serán retomados también como guías para el análisis del modelo de acumulación.

Una vez establecidas las similitudes, señalaremos las diferencias constitutivas entre ambos conceptos. En primer lugar, hay una diferencia de escala temporal clave: mientras que el concepto de régimen de acumulación abarca largos periodos (por ejemplo, patrón de acumulación neoliberal, 1976-2001), el modelo de acumulación remite a recortes temporales más breves (modelo de Convertibilidad, 1991-2001). Esto conduce a una segunda distinción: es posible hallar distintos modelos dentro de un mismo régimen de acumulación. Si en un nivel de mayor generalidad es posible encontrar similitudes entre modelos como para pensarlos como parte de un mismo régimen, en un nivel de mayor especificidad veremos diferencias en el plano de la estructura económica, en las políticas y las relaciones entre fracciones de clase. Entonces podemos pensar el modelo de acumulación como un subperiodo del régimen de acumulación. De este modo, el concepto modelo de acumulación desciende niveles de abstracción para interpelar el proceso de acumulación en un periodo más acotado donde regularidad y prelación pueden ser observadas con mayor especificidad. Además encontramos una tercera diferencia: el recorte espacial. Mientras que un régimen de acumulación puede cubrir un amplio conjunto de formaciones sociales, el modelo de acumulación se acotará a una sola formación social (en este caso, Argentina).

1 Véase Gramsci, 2003. 


\section{El fin del modelo de Convertibilidad}

El modelo de acumulación actual tuvo su origen en el contexto de crisis integral que marcó el fin del modelo de Convertibilidad. Este modelo había encarnado la forma más acabada de aplicación de las reformas neoliberales como profundización de la ofensiva del capital efectivizada a partir del golpe de Estado de 1976. Estuvo caracterizado por la desregulación, la privatización masiva de empresas públicas y la precarización laboral. Asimismo, poseía cualidades que lo hacían intrínsecamente deuda-dependiente debido a la necesidad de divisas para mantener la paridad \$1-US \$1 del tipo de cambio fijado por ley. El endeudamiento se vinculó al escaso dinamismo de las exportaciones, con apertura comercial y moneda sobrevaluada, y un constante déficit fiscal (entre otras causas, por el impacto producido por la privatización del sistema de jubilaciones y pensiones). Así pues, la vulnerabilidad externa, evidenciada en el desequilibrio de la cuenta corriente, se vio agudizada por la profundización del proceso de fuga de capitales, ligado principalmente a mecanismos de valorización financiera.

Ante los crecientes signos de agotamiento del modelo de Convertibilidad, se fue generando una fractura de intereses entre distintos sectores del capital que buscaban mejorar su capacidad de apropiación del excedente con base en dos propuestas divergentes de salida (Basualdo, 2001; Castellani y Szkolnik, 2005; Schorr y Wainer, 2005). Dichas propuestas se relacionaban con las diferentes posiciones ${ }^{2}$ ocupadas en la estructura y con las estrategias de acumulación de las distintas fracciones. Por un lado, comenzaron a aglutinarse diversos agentes económicos, principalmente ligados al capital productivo y exportador, promoviendo la devaluación para mejorar su competitividad e inserción en el mercado mundial, así como valorizar las ingentes masas de capitales que se mantenían fugadas en el extranjero. Otro núcleo de agentes, vinculados al capital financiero y las empresas de servicios privatizadas, exigieron la dolarización para mantener el valor de sus activos en dólares y garantizar la perpetuación de los beneficios de la convertibilidad de la moneda, como el envío de remesas dolarizadas al exterior. La capacidad de la propuesta devaluacionista para construir alianzas más amplias (Castellani y Szkolnik, 2005), las limitaciones objetivas del proyecto dolarizador y el desenvolvimiento efectivo de las variables económicas favorecieron la salida devaluacionista.

2 La noción de posición será utilizada en dos dimensiones: a) en relación con el lugar ocupado en la estructura económica y $b$ ) en términos de relación de fuerzas (como posición relativa). La articulación de ambas dimensiones nos permitirá pensar la distribución de "cargas" y "beneficios" del modelo de acumulación. 


\section{La configuración del modelo Posconvertibilidad}

\subsection{Las políticas fundacionales}

El modelo Posconvertibilidad comenzó a configurarse a partir de seis políticas fundacionales: 1) la devaluación, 2) la aplicación de retenciones a la exportación, 3) la pesificación asimétrica de deuda privada, 4) el salvataje al sector financiero, 5) el default y 6) el congelamiento de tarifas. Estas políticas instauraron nuevas reglas de juego, delimitando variaciones en el campo de acción de los agentes económicos, los cuales se relacionaron conflictivamente con las mismas y entre sí, en la disputa del excedente económico. Estas políticas fundacionales fueron dando lugar a un nuevo modelo de acumulación, que presentó rupturas y continuidades respecto del modelo de la década de 1990, y se vincularon con cambios particulares en la correlación de fuerzas, definiendo un reparto diferencial de cargas y beneficios. Las transformaciones que señalaremos permiten pensar que comenzó a gestarse una experiencia de régimen neodesarrollista en la región.

\subsection{La centralidad del capital productivo-exportador}

La devaluación generó un tipo de cambio internacionalmente competitivo que dio lugar a la dinamización de las exportaciones y, a través de su gravamen mediante retenciones, a la recomposición de las cuentas públicas. La recuperación económica conllevó un aumento de la producción manufacturera, impulsada por la dinámica exportadora e incluyendo un fenómeno periférico de sustitución de importaciones producto de la protección generada por la modificación del tipo de cambio. Por otra parte, el efecto inflacionario ligado a la devaluación redujo sustancialmente el salario real, y junto con el congelamiento relativo de las tarifas de servicios, los elevados precios de los commodities y el nuevo tipo de cambio, permitió a los agentes productivoexportadores generar elevados márgenes de ganancia y recuperar niveles de actividad económica. Los gobiernos desarrollaron una política activa para mantener el tipo de cambio competitivo y alentar esta vía de expansión económica a partir del crecimiento de las exportaciones, que aumentaron un $121 \%$ entre 2002 y 2007.

Las principales actividades exportadoras se encuentran en el complejo de oleaginosas, explicado casi totalmente por las actividades sojeras, que participan de $23.3 \%$ del valor total exportado (2005). Si al complejo de oleaginosas se le suman el cerealero, el bovino y el frutihortícola, el conjunto de estas actividades representa $41.7 \%$ del valor total exportado. El segundo complejo exportador es el petrolero-petroquímico, con un $19.1 \%$ de las exportaciones, centrado en la venta de petróleo y gas. De este 
modo, observamos que el núcleo dinámico de la economía argentina está representado por agentes productivos orientados a la exportación, basada en la explotación de los recursos naturales, marcando la consolidación de una estructura productiva regresiva, sustentada en la producción de productos primarios y de manufacturas con escaso valor agregado. También la industria automotriz continuó con una fuerte presencia, representando $8.6 \%$ de las exportaciones, en el marco de las políticas de promoción a dicho sector que continuaron desde la década de 1990, aunque sus principales actividades están vinculadas a la ensambladura de los automotores y no a la producción de partes de alto valor agregado.

Otro factor a destacar: $52 \%$ de las ventas al exterior correspondió a la suma de manufacturas de origen agropecuario y productos primarios que son, asimismo, bienes de consumo masivo de la población. Esto repercute desfavorablemente en el nivel de inflación ${ }^{3} \mathrm{y}$, por ende, en las condiciones de vida de los sectores populares . $^{4}$

También debemos señalar que, como en el modelo anterior, continuó un perfil altamente concentrado del sector exportador. Así pues, sólo las 25 primeras empresas líderes en exportación explican 62.9\% del valor total exportado (Schorr y Wainer, 2005). El dinamismo y concentración de estos agentes nos permiten pensar en una fracción productivo-exportadora del capital como núcleo dinámico del modelo Posconvertibilidad, que tiende a presentar niveles de rentabilidad y ventas superiores al resto de los sectores de la economía. La denominación productivo-exportadora de esta fracción no refiere a que sea únicamente exportadora, sino a que en la configuración del modelo Posconvertibilidad, el impulso que ha cobrado esta orientación exportadora ha permitido alcanzar un considerable superávit comercial que aunado al superávit fiscal, favorecido mediante retenciones a las exportaciones, configuran los dos pilares de estabilidad del modelo.

Estos agentes también fueron beneficiados por la pesificación asimétrica de deuda privada, mecanismo establecido durante el gobierno de E. Duhalde (2002-2003) para socializar las deudas del capital. Esta política implicó que los bancos debieron devolver los depósitos en dólares a \$1.40 por cada US \$1, mientras que los deudores con la

3 Es notorio en la tendencia del empresariado a dolarizar el precio de estos productos para equipararlos con los precios de exportación, constituyendo uno de los factores principales del proceso inflacionario que socava el salario real en la posconvertibilidad.

4 Si bien la soja no es un producto de consumo masivo de la población, su crecimiento por encima de los otros cultivos destinados a la alimentación restringe las tierras destinadas a los mismos. Además, el auge sojero ha impulsado aumentos en el precio de la tierra, incrementando los costos para todos los cultivos. 
banca local vieron pesificadas sus deudas en dólares a \$1 por US \$1. Cuando el lobby empresarial logró forzar al gobierno a derogar el techo impuesto inicialmente para la pesificación de deudas (US \$100 000), ésta se convirtió en un mecanismo de licuación masiva de las deudas del capital productivo y las privatizadas con la banca local.

En este contexto, el gobierno dispuso un plan de salvataje al sector financiero, destinado a compensar a dicha fracción del capital y a la banca pública por las consecuencias de la salida devaluacionista y la pesificación asimétrica, y que fueron cubiertas con emisión de nueva deuda pública por un monto total de US \$20.379 millones.

Estas políticas fortalecieron a las principales empresas industriales y agropecuarias, así como a algunas privatizadas, agravando la concentración económica. En términos generales, la concentración económica puede advertirse en el hecho de que las ventas de las 200 empresas más importantes, la cúpula empresarial, que en 1997 representaban $31.6 \%$ del PIB, en 2005 se elevaron a 51.3\%. Asimismo, es evidente una concentración dentro de la concentración, ya que las primeras 10 empresas de la cúpula crecen y acumulan a ritmos muy superiores al resto (Lozano, Rameri y Raffo, 2007). En el agro tuvo lugar un triple proceso de concentración, cuyas raíces se encuentran en transformaciones técnicas y tecnológicas de largo plazo: 1) Concentración estructural de la tierra, donde sólo $4.2 \%$ de las explotaciones agropecuarias (que poseen más de 2500 hectáreas) acapara $62.8 \%$ de las hectáreas totales. 2) Concentración del capital, presente tanto en el desdoblamiento creciente entre propietarios (convertidos en rentistas por el aumento de la escala de producción) y contratistas (propietarios de las maquinarias, con o sin tierra), a la que se suma la concentración del capital en la industrialización de granos, controlada en un $80 \%$ por sólo seis empresas. 3) Concentración de la organización y gestión del proceso productivo mediante grandes empresas agropecuario-financieras que utilizan la estrategia de armar pools de siembra.

La estructura económica argentina posee un alto grado de concentración y extranjerización, que permite cuestionar la idea de burguesía nacional, presente tanto en los discursos de los gobiernos de la Posconvertibilidad como en los de los grupos que más concentran el capital productivo, para quienes esa burguesía podría establecer una alianza virtuosa con los trabajadores. De las 500 mayores empresas, el 90\% de las utilidades se concentra en aquellas que poseen más de 50\% de capital extranjero. Ello no implica la desaparición del capital local, sino su subordinación a las lógicas transnacionalizadas de acumulación y al liderazgo de empresas de envergadura global. Las empresas extranjeras no sólo han recompuesto sus ganancias sino que superan ampliamente las obtenidas en promedio durante el modelo ante- 
rior, y a pesar de ello es muy poco lo que dejan en el país ${ }^{5}$. Resulta difícil imaginar una "burguesía nacional" independiente, mercado-internista, "aliada" con la clase trabajadora, cuando sus intereses se encuentran fuertemente transnacionalizados e incluso su composición está extranjerizada.

Por otra parte, la orientación exportadora del capital productivo, lejos de encontrar en el salario un factor fundamental (como consumo en el mercado interno) para la realización del capital, aparece como un costo para la empresa, que busca reducirlo para ganar rentabilidad. Esto puede observarse en el hecho de que una de las claves de la competitividad y las ganancias empresariales en la Posconvertibilidad se encuentra en que, en un contexto de aumento de la productividad laboral, la limitada evolución del salario real generó una fuerte reducción del costo laboral: salarios bajos en pesos aún resultan mucho más bajos en dólares, constituyendo un factor de competitividad internacional.

\subsection{Políticas de ingreso hacia las clases subalternas}

El momento de máximo deterioro del tejido social se experimentó en 2002 con los efectos del estallido inflacionario, que se perpetuó con aumentos que afectaron principalmente, por la estructura exportadora, los componentes de la canasta básica. Como señalan Costa, Kicillof y Nahón: "la inflación registrada (del 45\%) bastó para reducir los ingresos reales de los trabajadores en un tercio en el periodo 2001-2003" (2004: 83), a lo que se sumó la explosión de los índices de desocupación, pobreza e indigencia. En este contexto, los gobiernos de N. Kirchner (2003-2007) y de C. Fernández de Kirchner (desde diciembre 2007) han desplegado determinadas acciones tendientes a apuntalar los ingresos mínimos de las clases subalternas y aumentar los salarios reales de modo más significativo en los sectores más dinámicos de la economía. Para lograrlo, se han establecido cuatro mecanismos: a) aumento del salario mínimo, b) impulso a los convenios colectivos, $c$ ) aumento y extensión de las jubilaciones mínimas y $d$ ) algunos acuerdos de precios para limitar la inflación.

Sin embargo, el impacto y alcance de estas medidas sobre la clase trabajadora ha sido dispar. Puede percibirse una fractura correspondiente a los distintos tipos de trabajo

5 "Aún hacia 2004, en un contexto de apreciable recuperación de la economía y con una renta de la IED que resultó un 55\% superior al promedio observado en la década del 90, las ETs remitieron utilidades por un monto mayor al obtenido en dicho año, y fue sólo en 2005, y con una renta que superó en un $120 \%$ al promedio de los 90 a pesar de la pérdida de valor del peso, que las utilidades reinvertidas cambiaron su signo: las ETs dejaron en el país el $9 \%$ de la renta obtenida" (Sacroisky, 2006: 41). 
asalariado. Por un lado, los trabajadores del sector privado, registrados y bajo convenio colectivo, han conseguido aumentos equivalentes o superiores al índice inflacionario, aunque sólo alcanzan al $14.7 \%$ de la fuerza laboral (Gambina et al., 2006). Por otro lado, se encuentra la masa de trabajadores informales, cercana al $40 \%$, a los que se les suman los trabajadores estatales, cuyos salarios quedaron sepultados por la inflación y su nivel de vida se deterioró en relación con 2001.

Por otra parte, el perfil más productivo del modelo ha tenido un impacto positivo sobre el empleo, reduciendo significativamente la desocupación, de $23.3 \%$ en 2002 a 7.3\% en el trimestre 2007-IV. Pese a ello, no se han producido avances significativos en la distribución del ingreso. En materia de distribución funcional, aunque los trabajadores mejoraron sus salarios en relación con 2002, en términos generales quedaron por debajo de su participación de 2001, presentando además una creciente fragmentación salarial.

Se gestó así un modelo de capitalismo "normalizado" que genera inclusión mediante el descenso de la desocupación y mantiene una estructura salarial que garantiza elevadas ganancias al capital concentrado, al mismo tiempo que pone un piso salarial recomponiendo márgenes de legitimidad. A esto se le agrega la recuperación del poder adquisitivo de una minoría de asalariados y el consenso proveniente de la recuperación del consumo. El nuevo modelo ha mostrado capacidad de impulsar el crecimiento del PIB y de proveer niveles de vida relativamente similares a los del modelo de la Convertibilidad, pero vale recordar que incluso en sus mejores momentos ambos modelos representan la consolidación de una Argentina desigual, con una clase trabajadora fragmentada por la dispersión salarial y sus distintas formas de inserción (o no) al mercado laboral.

\subsection{Deuda pública y capital financiero}

Las políticas vinculadas a la deuda pública tuvieron un claro impacto en las relaciones de clase, en tanto una parte considerable de los bonos en default estaban en poder de los conglomerados financieros, que habían visto perjudicadas sus posiciones relativas por la salida devaluacionista y pesificadora y que habían comenzado a ser compensados en 2002 mediante la emisión de nueva deuda.

La salida del default ${ }^{6}$ concretada con el canje de 2005 presentó una quita final del

$6 \quad$ El análisis detallado del enfoque expresado sobre deuda pública puede verse en Varesi, 2008. El default no había afectado a la deuda con organismos financieros internacionales. Éstos fueron asumidos como acreedores privilegiados llegando al cancelamiento por adelantado de la deuda con el FMI. 
43.4\% sobre el total canjeado. Uno de los elementos más novedosos del canje son las Unidades Ligadas al PIB, cupones que, en las condiciones de crecimiento económico reciente, produjeron ganancias que se multiplicaron año tras año ${ }^{7}$. El segundo elemento relevante es que cerca de $47 \%$ de la deuda se encuentra pesificada e indexada a la inflación ${ }^{8}$. La indexación de deuda a la inflación debe ser entendida como una medida que garantiza al capital financiero no perder más posiciones respecto del capital productivo, principal beneficiario del ciclo inflacionario. Al mismo tiempo, representa una doble extracción a las clases subalternas: el traspaso de recursos que implica la inflación y la carga interminable de la deuda pública financiada por una estructura tributaria regresiva.

Aun con la importante quita del canje, queda un calendario de pagos con desembolsos anuales hasta por US \$20 000 millones. La magnitud del endeudamiento es tal que ya en 2007, apenas dos años antes del canje, con los recursos del superávit fiscal el Estado únicamente pudo afrontar poco más de un tercio de los pagos, y tuvo que endeudarse con el solo fin de pagar la deuda. El canje y la continuidad del ciclo de endeudamiento representan la cristalización de una nueva transferencia masiva de ingresos de asalariados a capitalistas, ya que recompone las relaciones en la clase dominante a costa del conjunto de la sociedad. Incluso finalizado el canje, la deuda quedó por encima de los valores de 2001, y continúa creciendo.

Los recursos fiscales destinados a la deuda superan la suma del presupuesto para salud, educación, vivienda y agua potable, es decir, el gasto social que define la calidad de vida de los sectores populares (Lucita, 2005). Los primeros gobiernos de la Posconvertibilidad mantuvieron el ajuste en el gasto primario real ${ }^{9}$, derivando estos recursos hacia el pago de deuda.

\subsection{Estructura impositiva}

Otro aspecto donde las acciones estatales no han mostrado avances significativos es en materia de estructura impositiva. El IVA, impuesto de naturaleza regresiva, explica

7 El Estado debió pagar en materia de las Unidades Ligadas al PIB \$1 242 millones adicionales de deuda en 2006, que se duplicarían en 2007, alcanzando los \$2 450 millones.

8 El gobierno mantiene intervenido al INDEC con el fin de manipular el índice de inflación y de este modo, limitar el impacto de la deuda. Esto tiene consecuencias en la construcción de los indicadores sociales.

9 Según el Ministerio de Economía, el gasto primario real promedio del periodo 2002-2006 representa \$44 745 millones, comportando un descenso del 15\% del periodo recesivo 1999-2001, de $\$ 52165$ promedio. 
más de 30\% de la recaudación. Es seguido por el impuesto de Ganancias, que hasta la reforma de 2007 afectaba a amplios sectores de trabajadores. Apenas en cuarto lugar, luego del tributo de Seguridad Social, aparecen las retenciones (principal insumo del tributo de Derechos al comercio exterior), que representan un 13\% de la recaudación. Este impuesto marca una novedad: por un lado, busca desdoblar los precios del mercado externo e interno procurando limitar la inflación que afecta principalmente a las clases subalternas; por otro lado, se grava la fracción más dinámica del capital (productivo-exportador), para derivar riqueza, por medio de deuda al capital financiero. Representa un intento de construir gobernabilidad a partir de la compensación de distintos intereses de clase. Por una parte, las retenciones, limitando el proceso inflacionario, acompañan a las medidas de apuntalamiento del salario. Por la otra, las retenciones incrementan el superávit primario que será destinado al pago de deuda y que acompañan a otras acciones: tanto las compensaciones a los bancos (en 2002) como la salida del default, que incluye cupones atados al crecimiento y bonos en pesos indexados a la inflación. También debemos señalar que las retenciones serían un factor de creciente diferenciación al interior de la fracción productivo-exportadora, entre quienes aparecen gravados por ellas y quienes quedan exentos y muchas veces son beneficiarios de otras transferencias como subsidios o beneficios impositivos.

\subsection{Estrategia estatal heterogénea y empresas privatizadas}

El fin de la Convertibilidad perjudicó las posiciones relativas de la mayoría de las empresas privatizadas ${ }^{10}$. Si en 2002 se establecieron las herramientas legales iniciando el congelamiento y renegociación de tarifas, durante el gobierno de N. Kirchner se desplegó una estrategia heterogénea consistente en tres acciones estatales diferenciadas: renegociación, reestatización y creación empresarial. Esta estrategia perseguía tres objetivos: 1) desmantelar los procesos judiciales que muchas privatizadas llevan adelante en el Centro Internacional de Arreglo de Diferencias Relativas a Inversiones (CIADI); 2) evitar un "tarifazo", limitando la inflación y buscando mantener el nuevo esquema de precios relativos favorable a la producción de bienes transables; y 3) aumentar la influencia del Estado en determinadas áreas.

Para las renegociaciones, el gobierno ha utilizado la prórroga de los principales contenidos de la Ley de Emergencia Pública que dispuso el congelamiento tarifario y la revisión de contratos y tarifas. Las renegociaciones tendieron a presentar aumentos

10 Una ampliación de este tema puede ser leída en Varesi, 2009. 
de entre $15 \%$ y $30 \%$ (por ejemplo, Edesur, Edenor y Gas Natural Ban); muchos se dirigieron principalmente a los grandes consumidores, y aunque evitaron el tarifazo directo, impactaron en la población por la transferencia parcial del aumento de costos a precios. Si bien en todos los casos el acuerdo implicó el retiro de las demandas del CIADI, a las privatizadas no se les exigieron las inversiones incumplidas.

Las reestatizaciones fueron realizadas por fuera de las figuras legales para empresas estatales, evitando así una serie de controles. Se formaron sociedades anónimas, consignadas bajo la Ley núm. 19550 que regula y tipifica las sociedades comerciales, con mayoría accionaria estatal. Esto sucedió con el Correo Argentino, Aysa, el espacio radioeléctrico, y hubo reestatizaciones parciales como Aeropuertos y el Ferrocarril San Martín. Esta acción estatal parece una clara ruptura con el paradigma de gestión de la década de 1990.

La tercera variante fue la creación empresarial por parte del Estado. Éste fue el caso de Energía Argentina S. A. (Enarsa), creada como parte de la política energética del gobierno para incidir en esta área clave. Sin embargo, Enarsa representa ciertos aspectos de continuidad con las políticas de los noventa, ya que se ha convertido en una herramienta de cuño estatal para la penetración de las corporaciones a la explotación de la cuenca marítima, último reducto de reserva petrolera sin privatizar. Además, ofrece beneficios impositivos para promover, de forma conjunta, la explotación y exploración, tarea incumplida por las privadas del sector que han generado un "saqueo" del recurso (reducción de 60\% y 68\% de las reservas de petróleo y gas, respectivamente, desde su privatización). Al mismo tiempo, Enarsa permitió recuperar la participación estatal en el sector energético promoviendo también planes de acción junto con otras petroleras estatales latinoamericanas como medio de integración.

Los gobiernos de la Posconvertibilidad, aunque han asumido una postura de mayor firmeza frente a las privatizadas, no han propuesto un plan integral de recuperación de los recursos estratégicos. En la actualidad, las privatizadas ocupan una posición subordinada respecto de la década de 1990, época en que representaban sólo $13 \%$ de las empresas de la cúpula empresarial, pero explicaban aproximadamente 57\% de las ganancias totales de la misma (Azpiazu y Basualdo, 2004). Si bien en el modelo actual las empresas de servicios públicos privatizadas (a diferencia de las privatizadas productivo-exportadoras) han perdido posiciones al interior de la cúpula empresarial, se ha desplegado una política de subsidios "compensatorios" que alcanzaron los $\$ 6700$ millones anuales para el sector transporte y $\$ 9230$ millones para el sector energético en 2007. 


\subsection{Conclusiones preliminares}

Observamos que en el periodo 2002-2007 se configuró un nuevo modelo, que procura saldar la crisis de 2001, en el que el Estado emerge como un actor fundamental en la movilización de recursos a través de diversos mecanismos de transferencias. Estos mecanismos, enlazados con los cambios en la correlación de fuerzas entre las distintas fracciones de clase, buscaron gestar un nuevo momento conciliatorio en la administración de la fase expansiva del ciclo económico. El perfil productivo-exportador del modelo, las nuevas modalidades de intervención estatal, el conjunto de rupturas en materia de variables y políticas económicas, junto con otras como el impulso de la obra pública en infraestructura, sugieren la gestación de un nuevo régimen de acumulación de carácter neodesarrollista.

\section{Crisis mundial y políticas anticrisis}

\subsection{El advenimiento de la crisis mundial: periodización e impactos}

En este contexto comenzaron a manifestarse los primeros síntomas de la crisis mundial. Ésta puede ser pensada, en el largo plazo, como corolario del neoliberalismo (Féliz, 2009), producto de las transformaciones estructurales que caracterizaron la ofensiva mundial del capital sobre las clases subalternas a partir de la precarización laboral, la contracción salarial y los procesos privatizadores en el marco de la desregulación y liberalización económica. Estas dinámicas de acumulación condujeron al sobredimensionamiento de las actividades financieras especulativas (Amín, 2008), al tiempo que generaron una crisis de sobreproducción y subconsumo (Borón, 2009). En el mediano plazo, se conjugaron la profundización del endeudamiento público y privado en los EEUU y el impulso de "políticas de la burbuja económica" (Brenner, 2008) junto con el surgimiento de nuevas resistencias y gobiernos alternativos en América Latina, generando trabas a las planificaciones del centro, como en el caso del Área de Libre Comercio de las Américas (ALCA) (Gambina, 2009). En el corto plazo, aunque el estallido de la burbuja financiero-hipotecaria en los EEUU fue el detonador de la crisis, ésta evidencia tensiones más profundas del capitalismo, imponiendo un panorama recesivo a escala mundial que no trasluce sólo una crisis de dimensiones económicas sino que se articula con dimensiones energéticas, alimentarias y ecológicas, que hacen pensar en una verdadera crisis de la civilización.

El modelo Posconvertibilidad había emergido en Argentina en el contexto de las luchas enmarcadas en aquel mediano plazo de la crisis mundial y surgió como res-

puesta condicionada de normalización capitalista en medio de una profunda crisis

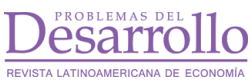

Vol. 41, núm. 161, abril-junio / 2010 
integral a escala nacional. Expresa rupturas y continuidades respecto del modelo anterior, el más característico del régimen neoliberal, promoviendo una experiencia neodesarrollista en la región.

La crisis mundial alcanzó a Argentina en una etapa en que mostraba cinco años de crecimiento a tasas cercanas a $9 \%$. Esta crisis cuenta con la singularidad de que se gestó en los países centrales y fue en los primeros donde se propagó; por el peso de sus economías en el contexto de mundialización del capital, terminó por afectar al conjunto de las economías nacionales, en distinta medida según las particularidades de los modelos de acumulación y su grado de apertura y vinculación a las economías centrales. En lo que respecta a la Argentina, podemos identificar dos mecanismos de propagación principales: el impacto en materia de comercio exterior, ligado a la caída del comercio mundial y los precios de los commodities, y el ajuste en los planes de producción de las empresas.

Según un informe de la Fundación de Investigaciones Sociales y Políticas (FISYP): "Como sucedió en el mundo entero, las exportaciones argentinas descendieron. En el primer trimestre del 2009 se redujeron un $26 \%$ respecto al mismo periodo del 2008" (FISYP, 2009: 4), con fuerte contracción en productos primarios. Se produjo una circunstancia importante para el modelo: "el crecimiento continuo de las exportaciones, desde la devaluación, se quiebra en el tercer trimestre del 2008” (FISYP, 2009: 5). Esta dinámica exportadora se relacionó, junto con la caída de demanda externa en términos de cantidades, con la fuerte vinculación a los vaivenes del precio de los commodities: éste se desplomó desde julio de 2008 hasta febrero de 2009, cuando el índice general de precios de commodities quedó por debajo de su valor de 2005, aunque a partir de ahí pareciera comenzar a revertirse la tendencia ${ }^{11}$. El mantenimiento de la reestructuración productiva regresiva y la apertura económica tornaron a la economía argentina subordinada al precio internacional de los commodities, marcando el papel dependiente de su inserción internacional. Como señalamos, el crecimiento de la fracción productivo-exportadora del capital ha tenido cardinal importancia en el desarrollo del modelo, en cuanto ha habilitado un considerable superávit comercial y cuyo gravamen a través de retenciones a las exportaciones favoreció la consecución del superávit fiscal. Ambos superávit conforman los dos pilares de estabilidad del modelo, por lo que la contracción del superávit comercial podría provocar tanto la restricción de divisas como un debilitamiento de las cuentas fiscales, ambas de relevancia para el sostenimiento del sistema de transferencias de ingresos. Un dato

11 Datos INDEC tomados del FMI. 
significativo es la disminución del superávit comercial, que según el IEF-CTA ${ }^{12}$, en enero 2009 "se redujo un $27 \%$ respecto al año anterior, por efecto de la caída del volumen de exportaciones (-35.8\%), que fue compensada por una mayor caída del volumen de importaciones (-38.4\%)" (Lozano, 2009: 6). Esta situación comenzó a revertirse desde abril de 2009, acompasando la variación del precio de los commodities.

El segundo mecanismo refiere al ajuste de planes productivos por parte de las empresas. Este factor podría afectar en dos aspectos fundamentales: a) caída en la inversión, y $b$ ) incremento de fuga de capitales; y junto con el deterioro del comercio exterior conllevarían a: $c$ ) desaceleración del crecimiento y retracción industrial y d) aumento del desempleo.

La desaceleración económica se plasmó en la variación anual del PIB, que de 69\% en el trimestre 2008-III se retrotrajo a $4.1 \%$ en el trimestre siguiente, y cayó hasta el $2 \%$ en el trimestre 2009-I. Esto se relacionó principalmente con la caída en la producción de bienes cuya variación anual pasó de 3.9\%, a -0.7\% y alcanzó el -3.2\%, respectivamente, para los trimestres mencionados. Este descenso de la producción de bienes tiene su correlato en la industria. El Estimado Mensual Industrial, reflejo de la evolución del sector industrial, muestra que entre septiembre de 2008 y marzo de 2009 la actividad industrial cayó un 6\% (FISYP, 2009). En este marco: "Las industrias más afectadas son particularmente las que explicaron y motorizaron el crecimiento de la industria en los años precedentes. Es el caso de la Industria Automotriz, la Industria Textil y la Industria Metal Mecánica Básica” (FISYP, 2009: 6).

Si tenemos en cuenta que en la posconvertibilidad, la industria se transformó en un importante generador de empleo, hasta colocarse como un factor de inclusión y legitimidad del modelo, su contracción no puede dejar de debilitar este papel. Además, la crisis afectó a la construcción, otro dinámico sector empleador; ésta creció entre 2003-2007 a un 22.4\% anual pero en 2008 se desaceleró, sólo creció 3\%. Como principal impacto, ya en 2007 se frena la creación de nuevos puestos de trabajo, cortando una tendencia ininterrumpida desde 2003, y en 2008 comienza a elevarse el desempleo hasta $8.8 \%$ en el trimestre 2009-II.

La Inversión Bruta Interna Fija (IBIF) también se contrajo: de representar 23\% del PIB en el trimestre 2008-I pasó a 19.1\% en el trimestre en 2009-I, momento en que se produjo el pico más fuerte de reducción de la variación anual de las inversiones desde 2002: un -14.2\%. Más allá de la coyuntura, podemos observar una tendencia de más largo plazo de desaceleración de la IBIF, ya que su variación interanual se reduce in-

12 Instituto de Estudios y Formación de la Central de Trabajadores Argentinos. 
cesantemente desde 2003, mostrando una tendencia a la "huelga de inversiones" que no emerge en la crisis sino que se profundiza con ésta: 2003: 38.2\%; 2004: 34.4\%; 2005: 22.7\%; 2006: 18.2\%; 2007: 13.6\%, 2008: 9\%, exhibiendo ya valores negativos en su último trimestre. Este factor expresa otra vía de desgaste del modelo Posconvertibilidad, ya que sus políticas tendientes a la normalización capitalista no han logrado promover niveles de inversión privada que permitan prever el sostenimiento a largo plazo del modelo. Si el modelo Posconvertibilidad aparece como una salida hegemónica para el capital en su conjunto, la caída de las inversiones expresa una merma paulatina de su adhesión al mismo.

Otro factor que ilustra la disminución de confianza y apoyo por parte del capital hacia el modelo en el contexto de crisis, puede visualizarse en el crecimiento de la fuga de capitales. El IEF-CTA señala que en 2008 ésta alcanzó los US \$23 098 millones, implicando que "la fuga de capitales prácticamente triplicó a la del año anterior" (Lozano, 2009: 5).

\subsection{El plan anticrisis: políticas e impactos}

En este contexto, el gobierno comenzó a desarrollar un extenso plan anticrisis, en el que se destacan tres componentes. El primero comprende acciones estatales que no son presentadas por el gobierno como políticas específicamente anticrisis, pero desempeñan un papel singular en el desarrollo y supervivencia del modelo y tienden a establecer modificaciones en la correlación de fuerzas entre las fracciones de clases; los otros dos componentes son expresados oficialmente como parte del plan anticrisis y constan, por un lado, de un conjunto de políticas orientadas hacia el capital y, por otro, de un paquete de medidas sociales dirigidas específicamente hacia las clases subalternas. Los tres conjuntos de acciones estuvieron encaminados a mantener los pilares de estabilidad del modelo y a suavizar el impacto de la crisis mundial sobre el crecimiento del PIB y el empleo.

Una primera acción que procuró fortalecer las cuentas fiscales y moderar el proceso inflacionario fue la Resolución 125, de marzo de 2008, que aplicaba un aumento de las retenciones a los principales productos del agro con base en un esquema móvil, cuyos precios internacionales se habían duplicado en un corto plazo, y afectaba en mayor medida a la soja. Este hecho marcó un hito de carácter político en la era posconvertibilidad, ya que fue confrontado contundentemente por las patronales agropecuarias dando lugar a un conflicto con altos grados de movilización, cortes de ruta

y desabastecimiento, que se prolongó hasta la derrota de la 125 en el Parlamento, a mediados de julio del mismo año. Este evento mostró el grado de acumulación de 
fuerzas realizado por este sector de la fracción productivo-exportadora, anclado en el triple proceso de concentración previamente mencionado, y que fue generando un entrelazamiento de intereses al interior del sector y un creciente poder social que lo llevó no sólo a confrontar con un gobierno característico del modelo que les garantizó ganancias históricas, sino a derrotarlo en la arena política ejerciendo un duro golpe a su capacidad de generar adhesión.

A esto se sumó también la creciente presión de las corporaciones industriales por incrementar la devaluación. El gobierno entonces pondría fin a la relativa estabilidad cambiaria en términos nominales que había rondado los $\$ 3$ por dólar, aumentando gradualmente hasta llegar a $\$ 3.83$ en agosto de 2009. Con esta acción procuró mantener la competitividad internacional del tipo cambio para contrarrestar el efecto negativo que la crisis mundial estaba ejerciendo sobre las exportaciones.

Un momento fundamental fue la estatización de las AFJP (Administradoras de Fondos de Jubilaciones y Pensiones). La creación de las AFJP en la década de 1990 estableció un sistema jubilatorio mixto, donde el capital financiero usufructuaba los fondos de los trabajadores cobrando altas comisiones y provocaba gran parte del déficit fiscal de dicha época, en tanto el Estado dejaba de percibir aportaciones pero seguía pagando jubilaciones. En este contexto, las AFJP se transformaron en acreedores primordiales del Estado, cobrando altas tasas de interés, al punto de que más de $50 \%$ de sus fondos estaban invertidos en bonos de deuda pública. Ante el advenimiento de la crisis, los fondos jubilatorios invertidos por las AFJP padecieron una fuerte depreciación, argumento que empleó el gobierno para realizar su estatización. Con esta acción, el Estado transfirió fondos acumulados por $\$ 97000$ millones y recibiría aportaciones anuales calculadas entre $\$ 12000$ y 15000 millones. Podemos suponer que uno de los objetivos principales de esta medida era fortalecer las cuentas fiscales con el fin de hacer frente a los pagos de la deuda pública que para 2009 aumentarían a US \$20 000 millones. Esta acción estatal fue clave para mantener el superávit fiscal, uno de los pilares del modelo, ya que en enero de 2009 el superávit primario se redujo en un 40\% respecto del mismo mes del año anterior, y sin la aportación adicional de los fondos jubilatorios transferidos al Estado hubiera resultado deficitario. Además, varias medidas anticrisis serían financiadas a partir de los fondos manejados por el Anses ${ }^{13}$. Pero esta acción también marca un nuevo cambio en la correlación de fuerzas, en tanto los conglomerados financieros serían expropiados de un millonario

13 Administración Nacional de Seguridad Social, controla los fondos del sistema de jubilaciones y pensiones. 
negocio que habían usufructuado desde la ola de privatizaciones de los noventa.

Otro elemento dentro de este primer componente de medidas es el tarifazo. Si antes señalamos que las empresas de servicios privatizadas habían experimentado una considerable disminución de sus rentabilidades, la habilitación de aumentos tarifarios de relevancia, principalmente en materia de transporte, luz, agua y gas, constituyó un nuevo momento compensatorio. En el caso del transporte público, el $1^{\circ}$ de enero 2008 se habilitaron aumentos de un $20 \%$ promedio, afectando a trenes, subtes y colectivos. El argumento oficial consistió en que se reducirían los subsidios en $\$ 600$ millones; sin embargo, en ese año terminaron aumentándolos en \$3150 millones. Respecto del gas, en 2008 se habilitaron aumentos de tarifas escalonados que alcanzaron hasta un $400 \%$, con el fin de financiar un fondo para importar gas y realizar obras. Si bien las nuevas tarifas permitieron reducir en un $17 \%$ los subsidios al sector energético (gas y electricidad), en el primer semestre de este año comparado con el mismo periodo de 2008, siguió trasladándose a los usuarios la falta de inversión de las empresas. Por su parte, la luz presentó aumentos escalonados hasta un 200 por ciento ${ }^{14}$.

Según datos publicados por la Asociación Argentina de Presupuesto y Administración Financiera Pública, el monto de créditos destinados a subsidios en 2009 fue de \$32 700 millones, lo que representó una retracción de 5\% con respecto al total de créditos aprobados en 2008. Esto marca un cambio en las acciones estatales, en tanto, la partida de subsidios venía multiplicándose año tras año. En este sentido, se restringió la transferencia directa de recursos estatales pero se otorgaron aumentos tarifarios que los suplantan.

Las transferencias directas de recursos estatales al capital fueron complementadas con transferencias indirectas, mediante exenciones impositivas que cobraron forma en leyes de promoción de inversiones. Éste es el caso de la Ley de Promoción de Inversiones 26360 de 2008, que nos introduce en el núcleo de medidas oficializadas como parte del plan anticrisis, orientadas a dar respuestas a las demandas del capital. Esta ley mantiene continuidad con los regímenes anteriores (desde 2004) y promueve la compra de bienes de capital y el desarrollo de infraestructura, reduciendo aranceles

14 Según el sindicato del sector, Fetera: "El gobierno nacional, invierte más de 15000 millones de pesos anuales para sostener, en definitiva, las ganancias y las políticas de las empresas energéticas, casi todas extranjeras y exportadoras además de las rentas que obtienen; sin resolver problemas como el de la falta de abastecimiento de gas natural a la mitad de los habitantes argentinos, el de la construcción de generadores con combustibles más baratos o la reducción sustancial del precio interno de los hidrocarburos, que encarece enormemente el valor final del kilowatt" (Fetera, 2009). 
de importación y otorgando beneficios impositivos. Los fondos involucrados alcanzan los \$1 000 millones anuales, más \$200 millones destinados exclusivamente a PYMES. Sin embargo, Ortiz y Schorr (2009) señalan que estos regímenes de inversión han profundizado la concentración económica, promoviendo una estructura industrial muy sesgada hacia la producción de commodities y la "armaduría automotriz" e impidiendo contrarrestar la desintegración industrial de la década de 1990. Según los autores: "se trató de una fenomenal transferencia de recursos públicos hacia Aluar, Techint, Aceitera General Deheza, Repsol-YPF y las terminales automotrices, entre otros capitales oligopólicos; es decir, hacia empresas y conglomerados económicos que conforman el núcleo de los grandes ganadores del "modelo de dólar alto" y, como tales, seguramente hubieran realizado las inversiones" (Ortiz y Schorr 2009: 6).

El plan anticrisis también incluyó un fondo de \$13 200 millones para incentivar el consumo de sectores de ingresos medios y altos a través de créditos para la compra de autos cero kilómetros, utilitarios, camiones y electrodomésticos, así como para prefinanciar exportaciones y capital de trabajo para la industria y el sector agropecuario.

Dentro del grupo de medidas orientadas al capital, se encuentra el blanqueo de capitales. Éste procuró contrarrestar la presión de la fuga de capitales buscando la declaración de los fondos de los residentes locales en el exterior y su inversión en la economía argentina. Para lograrlo se propusieron descuentos tributarios, de modo que quienes participaron en esta medida pagaron entre $1 \%$ y $8 \%$, en vez del $35 \%$ del impuesto a las Ganancias, según distintas opciones que van desde la inversión productiva hasta la mera declaración del fondo.

Otra medida consistió en una amplia moratoria impositiva que condonó parte de la deuda a pagar y suspendió las acciones penales ya iniciadas contra los evasores. Además, ofreció bajas tasas de interés y un plazo de pago de hasta 120 meses. Esta acción apuntó a que el Estado recaudara en el corto plazo el 6\% de las deudas, como pago necesario para incorporarse al régimen de regularización de impuestos.

Dentro del vasto plan anticrisis, algunas medidas se orientaron a mejorar las condiciones laborales de la clase trabajadora mediante incentivos al capital. Una medida en este sentido implicó que los patrones que registraron o rectificaron la remuneración real o la fecha real de inicio de sus trabajadores, hasta 10 inclusive, obtuvieran la liberación de las infracciones, multas y sanciones. Otra, empalmada con la moratoria tributara, proporcionó beneficios a quienes regularizaron las aportaciones previsionales de sus trabajadores.

Una acción que aunque fue inaugurada antes de la crisis se profundizó durante la misma y que procura mantener el nivel de empleo a través del subsidio al capital, 
es el Programa de Recuperación Productiva (Repro). El programa otorga a empresas en crisis un subsidio mensual por trabajador de hasta $\$ 600$, de fondos del ANSES, para completar el salario. El beneficio se da sólo una vez por empresa y hasta por 12 meses. El programa se multiplicó: de 448 establecimientos en 2008 a unos 1492 en junio de 2009, con un alcance creciente: de 22846 trabajadores a 84628 en las fechas respectivas, casi cuadruplicando sus fondos. Destinado principalmente a la industria, el financiamiento mostró un sesgo tendiente a la concentración económica, ya que cerca de $41 \%$ del total se orientó a grandes empresas con más de 300 asalariados, aunque éstas sólo representaban 3.8\% de los establecimientos.

Un capítulo importante del plan fue la obra pública. En diciembre de 2008 el gobierno anunció un masivo plan de obra pública por \$111000 millones, con la finalidad de generar empleo y hacer frente a la desaceleración del crecimiento económico. El Plan Obras para Todos los Argentinos previó la distribución de los fondos en tres tipos de emprendimientos: obras de infraestructura vial y de mejoramiento del hábitat social (60\% de los fondos), y proyectos para mejorar y ampliar los sectores de energía eléctrica, gas natural y el transporte público de pasajeros, entre otros (40\%). Si bien este proyecto tiene un novedoso componente de inversión en las empresas públicas, también constituye una herramienta de fomento al capital más concentrado en mejor capacidad de disputar licitaciones y, en menor medida, a las PYMES. Por otra parte, muchas obras conllevarán beneficios directos para las condiciones de vida de las clases subalternas.

En cuanto a las medidas anticrisis orientadas explícitamente hacia los trabajadores, debemos destacar el aumento del salario mínimo, que pasó escalonadamente de \$1 240 a $\$ 1500$ en enero de 2010, con un impacto directo sobre 5.8\% de los trabajadores.

Finalmente, podemos señalar el paquete de medidas sociales, que incluyeron un conjunto de iniciativas como aumentos en el presupuesto del Plan Alimentario Nacional, un incremento de $50 \%$ en el adicional por hijo y la creación de 1000 cooperativas, cuyo impacto en el empleo se estima en 300000 puestos, entre otras. Estas medidas se enmarcaron en un aumento de $\$ 2000$ millones en las partidas destinadas a programas sociales. Sin embargo, debe observarse el escaso peso relativo de estas medidas en el conjunto del plan anticrisis, que según distintas mediciones representaron entre $1 \%$ y $7 \%$ de los fondos desembolsados en 2009. El IEF-CTA señaló que el plan anunciado no hizo más que especificar el destino de los fondos, que ya se habían aumentado en el presupuesto nacional de 2009, sin implicar una nueva medida anticrisis (Lozano, 2009). 


\section{Conclusiones}

El modelo Posconvertibilidad emergió como experiencia neodesarrollista tras la crisis de 2001 a partir de seis políticas fundacionales (devaluación, retenciones, pesificación asimétrica de deudas, salvataje al sector financiero, default y congelamiento tarifario) que ejercieron modificaciones en las relaciones de fuerzas entre las distintas fracciones de clase, al tiempo que el Estado comenzó a desplegar una serie de acciones "compensatorias" en busca de lograr adhesión y gobernabilidad. Se inició una fase expansiva de acumulación basada en una lógica productivo-exportadora, estructurada a partir de la exportación de materias primas y manufacturas de escaso valor agregado centradas en el procesamiento de los recursos naturales. Si bien se mantuvo la regresividad en materia productiva, el nuevo tipo de cambio impulsó la producción industrial y junto con el crecimiento de la construcción y de la economía en general promovió un modelo legitimado con base en la inclusión a través de la recuperación del empleo. Aun así, lejos de impulsarse una significativa redistribución del ingreso, el bajo costo laboral en condiciones de aumento de la productividad constituyó una de las claves fundamentales de la ganancia empresarial.

El surgimiento de la crisis mundial profundizó un cúmulo de tensiones propias del modelo y amenazó con desestabilizarlo mediante distintas vías. En este contexto, el gobierno desplegó un conjunto de activas políticas anticrisis que manifestaron la búsqueda por mantener tanto los pilares de estabilización del modelo Posconvertibilidad (superávit fiscal y comercial), como el statu quo establecido por el mismo. Las insuficiencias en materia de política social y salarial quedan expuestas ante la orientación masiva de recursos al capital por medio de subsidios y exenciones impositivas. Se expresaron algunas variaciones en las relaciones de fuerza al interior de la clase dominante: continuó un papel predominante del capital productivo-exportador, principal beneficiario de las políticas anticrisis, un repunte de las privatizadas a través del tarifazo y un debilitamiento del capital financiero a causa de la estatización de las AFJP. Sin embargo, quedó evidenciada la ausencia de una voluntad política de impulsar una aguda redistribución del ingreso. Se profundizó la función del Estado -característica en la conformación del modelo-, como actor fundamental en la implementación de mecanismos de transferencias de ingresos. Se corroboró también que esta función deja a los gobiernos con un importante grado de exposición frente a las fracciones predominantes del capital, aspecto que pudo observarse en la resistencia del agro, que constituyendo uno de los sectores más favorecidos del modelo, desató una ofensiva contra el aumento de las retenciones e infligió una seria derrota política al oficialismo. 
El plan anticrisis mostró la voluntad de dar continuidad al perfil productivoexportador del modelo y articuló iniciativas para mantener los dos pilares de estabilidad que lo sustentan y combatir el desempleo, aunque sin orientaciones redistributivas. Lejos de constatarse un modelo que "alíe" a trabajadores y capitalistas, las ganancias y la productividad quedaron por fuera de la discusión oficial. De este modo, el modelo avanzó profundizando la concentración y extranjerización económicas: el plan anticrisis transfirió cuantiosos recursos al capital y condonó sus faltas en amplias moratorias; aun así, la tendencia a la "huelga de inversiones" y la fuga de capitales se mostraron crecientes. Los salarios siguieron siendo depredados por el proceso inflacionario: la búsqueda de alternativas genuinamente transformadoras se tornan cada día más necesarias en un capitalismo mundial, cuya crisis tiende a ser descargada sobre las clases subalternas.
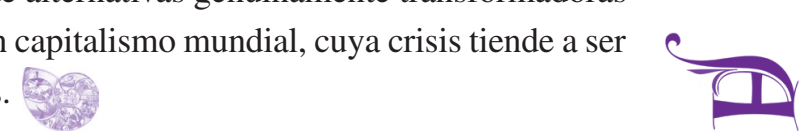

\section{Bibliografía}

Amín, Samir, ¿Debacle financiera, crisis sistémica? Respuestas ilusorias y respuestas necesarias, 29 de noviembre de 2008, http:// www.fisyp.org.ar/modules/news/article. php?storyid $=130$

Azpiazu, Daniel y Eduardo Basualdo, "Las privatizaciones en la Argentina. Génesis, desarrollo e impactos estructurales", en J. Petras y H. Veltmeyer (comps.), Las privatizaciones y la desnacionalización en América Latina, Buenos Aires, Prometeo, 2004.

Basualdo, Eduardo, Concepto de patrón o régimen de acumulación y conformación estructural de la economía, Documento núm. 1, Maestría en Economía Política Argentina, Área de Economía y Tecnología de la FLACSO, 2007, www.flacso.org.ar/ economía

, Sistema político y modelo de acumulación en la Argentina, Bernal, Universidad Nacional de Quilmes-FLACSO-IDEP, 2001.

Borón, Atilio, "De la guerra infinita a la crisis infinita", Ponencia presentada en el XI Encuentro Internacional de Economistas Globalización y problemas del desarrollo, $\mathrm{La}$ Habana, 2009.

Brenner, Robert, Una crisis devastadora en ciernes, $1^{\circ}$ de febrero de 2008, http:// www.iade.org.ar/modules/noticias/article. php?storyid $=2201$
Castellani, Ana G. y Mariano Szkolnik, Devaluacionistas y dolarizadores. La construcción social de las alternativas propuestas por los sectores dominantes ante la crisis de la Convertibilidad. Argentina 19992000, 2005, http://www.argiropolis.com.ar/ images/stories/ponencia\%20castellani.pdf

Costa, Augusto, Axel Kicillof y Cecilia Nahón, "Las consecuencias económicas del Sr. Lavagna. Dilemas de un país devaluado", Realidad económica, Buenos Aires, núm. 203, 2004, pp. 70-100.

Féliz, Mariano, "Frente a la economía política del capital, la economía política de la clase trabajadora: Alternativas populares frente a la crisis capitalista en Argentina", Ponencia presentada en el II Encuentro Internacional La economía de los trabajadores: trabajo y autogestión frente a la crisis global, Buenos Aires, Universidad de Buenos Aires, 2009.

Fetera, Resolución aprobada por el X Congreso Nacional Extraordinario de Fetera, 2009, http://feteranoaltarifazo.blogspot. com/2009/04/fetera-resolucion-sobre-tarifas.html

FISYP, Informe de coyuntura, primer trimestre 2009, 31 de agosto de 2009, http://www.fisyp.org.ar/WEBFISYP/INFCOY.doc

Gambina, Julio, América Latina y el Caribe: alternativas frente a la crisis, $1^{\circ}$ de mayo de 2009, http://www.fisyp.org.ar/WEBFISYP/ALAT09.doc 
Gambina, Julio et al., La política económica del gobierno argentino (2003/2006), 2006, www.fisyp.org.ar/WEBFISYP/GTTNI.doc

Gramsci, Antonio, "Análisis de las situaciones. Relaciones de fuerza", Notas sobre Maquiavelo, sobre la política y sobre el Estado moderno, Buenos Aires, Nueva Visión, 2003.

Lozano, Claudio, El cambio de fase en la etapa económica. De la desaceleración al estancamiento, 2009, http://www.cta.org. ar/base/ IMG/doc/El_cambio_en_la_fase_ economica_de_la_desaceleracion_al_estancamiento.doc

Lozano, Claudio y Tomás Raffo, Un paquete social insignificante: cómo anunciar 2 veces lo mismo, 2009, http://www.institutocta.org.ar/IMG/pdf/ UN_PAQUETE_SOCIAL_INSIGNIFICANTE.pdf

Lozano, Claudio, Ana Rameri y Tomás Raffo, Análisis y propuesta frente al presupuesto 2007, 2007, www.institutocta.org.ar/spip. php?article263

Lucita, Eduardo, Nueva reestructuración de la deuda, $1^{\circ}$ de marzo de 2005, http://www. rebelion.org/noticia.php?id=12054
Ortiz, Ricardo y Martín Schorr, "Crisis internacional y alternativas de reindustrialización en la Argentina", Ponencia presentada en el XXVII Congreso ALAS, Buenos Aires, 2009.

Sacroisky, Ariana, La Inversión Extranjera Directa en la post-Convertibilidad, Documento de trabajo núm. 2, Buenos Aires, CEFID-AR, 2006.

Schorr, Martín y Andrés Wainer, "Argentina: ¿muerte y resurrección? Notas sobre la relación entre economía y política en la transición del 'modelo de los noventa' al del 'dólar alto'", Realidad económica, Buenos Aires, núm. 211, 2005, pp. 32-65.

Varesi, Gastón A., "Empresas privatizadas y acciones estatales en el modelo post-convertibilidad, 2002-2007", Ponencia presentada en el XXVII Congreso ALAS, Buenos Aires, 2009.

"La actualidad de la deuda argentina. Resolución del default, actores y políticas en el modelo post-convertibilidad, 20022007" Periferias, Buenos Aires, núm. 16, 2008, pp. 111-134. 